\title{
From the Past Editor-In-Chief
}

\author{
Dear Readers of our ACM TOMM,
}

Following the sudden and very sad passing by my very close friend Nicolas D. Georganas, I became the new Editor-in-Chief in 2010. Nicolas is the founding Editorin-Chief of the ACM Transactions on Multimedia Computing, Communications, and Applications. He had made TOMCCAP/TOMM* one of the leading journals in the field of multimedia research. Since the very beginning, the annual ACM Multimedia Conference (ACM MM) and our journal have been the two key publication venues of the special interest group on multimedia (ACM SIGMM) and the wider community of multimedia researchers.

During my leadership of the journal in the previous 6 years, we have shaped the journal a lot. At the beginning, the time from submission of an article to a first decision was 90 days, on average. Through the introduction of a continuous screening of the review process, we were able to decrease this number to less than 50 days. Also the delay from acceptance of an article to its publication was reduced dramatically from roughly 2 years down to half a year. After the recent introduction of an article-by-article online publication model, this time span will decrease even more. These reduced delays together with other changes such as the inclusion of survey articles has increased the attractiveness of the journal. In order to honor Nicolas D. Georganas for his significant contributions to the multimedia research community, we introduced the ACM Transactions on Multimedia Computing, Communications, and Applications Nicolas D. Georganas Best Paper Award. This award is awarded annually to the authors of the most significant article published in TOMM in the previous year.

One key challenge for TOMM will be to find ways to keep upwith the changing landscape of scientific publication venues. The ACM Multimedia Conference is the most prestigious venue of SIGMM. We should find ways to collaborate so that the conference can benefit from the journal and vice versa. For several years now, TOMM has published the extended best papers of the conference. Starting last year, TOMM authors were invited to present their papers in a dedicated session of the conference. From my perspective, that is an excellent starting point to tighten this bond.

Another challenge is the crisp and up-to-date notion of the continuously evolving researchfield of Multimedia. Does it exclusively only include research that combines different types of media? Or shall it also cover research on a single media such as images being part of a multimedia environment? Discussions on aspects of theseissues have been going on in the community for several years; we should find a common agreement for our ACM Multimedia community and TOMM.

The whole development of TOMM would not have been possible without an excellent team. Our Associate Editors spend a lot of time and effort handling the articlesreading the articles initially, searching for reviewers, ensuring timely reviews and making decisions based on the reviews. The reviewers dive very deeply into the articles: trying to find flaws, rate articles and make suggestions to the authors how to improve the articles. The information director tracks the whole publication process and is available to handle upcoming issues. I would like to take the opportunity to thank everybody who has worked together with me in the previous 6 years to provide the

*The acronym was changed from TOMCCAP to TOMM in 2014.

2016 Copyright is held by the owner/author(s).

1551-6857/2016/06-ART37e

DOI: http://dx.doi.org/10.1145/2903774

ACM Trans. Multimedia Comput. Commun. Appl., Vol. 12, No. 3, Article 37e, Publication date: June 2016. 
readers of the journal with excellent and interesting research articles. This includes in particular also the authors of the articles who are contributing excellent research work.

Finally, I would like to wish Alberto del Bimbo and his team all the best for the future. I am looking forward to see how he will shape the journal in the future.

Dr. Ralf Steinmetz

Techn. Univ. Darmstadt "Outgoing Editor-in-Chief"

\section{From the New Editor-in-Chief}

Dear ACM TOMM Readers, Researchers in Multimedia,

In January 2016, we received the ACM TOMM journal from Ralf Steinmetz, Sebastian Schmidtand Lasse Lehmann. Together with the Associate Editors, they did a great job in the past 6 years, managing the reviewing process at a very professional level and reducing the time to publication to really amazing limits. ACM TOMM is today among the leading journals in the field of Multimedia. We will ever be grateful to all of them. Despite such impressive heritage, we want to improve its position even furtherwhile consolidating the ACM TOMM leadership. At the Editorial Board meeting in Brisbane in November 2015, I committed to improve ACM TOMM's international ranking and visibility. Given the quality and reputation of our competitors, this ambition will not be easy to obtain in one single appointment term, and will require a synergetic combination of several factors - the most important of all being a close cooperation and strong bond between SIGMM and TOMM's Editorial Board.

ACM TOMM is now published quarterly in printed form, plus two online issues: a publication rate significantly lower than its major competing journals. In the few past months we discussed with ACM the possibility of having more issues, and therefore more papers published per year. Particularly,we stressed the importance of having Special Issues on hot emerging topics managed by highly reputed researchers in the field. Our request for additional special issues has been granted. Therefore, starting in 2017,we expect to have four online Special Issues instead of two, that will accompany the four regular printed issues. Moreover, since we have an exceptionally qualified ACM TOMM Editorial Board, we plan to invite Editorial Board members to guest edit some Special Issues and Special Sections and write surveys on key subjects. We have already nominated five new Associate Editors who will help to have a broader coverage of the ever-expanding field of Multimedia. Other nominations will follow soon.

Other novel changes are on the table, and they will pose new challenges soon. ACM is going to launch a new journal series called PACM that will publish papers of top-quality ACM conferences willing to adopt journal review processes (see http://www.acm.org/ publications/policies/conference-proceedings-in-acm-journals). This will not conflict with $A C M$ TOMM but will eventually require us to rethink the way in which $A C M$ TOMM links to ACM Multimedia, in the case that conference decides to join the new program. Moreover, there is a growing trend from many sides to promote the integrity of the research ecosystem by developing review processes that increase the likelihood that published experimental results are valid. ACM is planning to define separate brands related to artifact review associated with research articles, to include appropriate evidence of verification and validation of reusability and reproducibility. Apparently, this is an interesting opportunity for ACM TOMM but will require modifications in its management and organization. 
Since January 2016, with the agreement of ACM, we have created the ACM TOMM Advisory Board. This Advisory Board will have no editorial duties but will support the Editor-in-Chief in the definition and implementation of strategies. I appointed the following colleagues as members of the ACM TOMM Advisory Board: Wen Gao, Peking University; Arnold Smeulders, University of Amsterdam; and Nicu Sebe, University of Trento. They will help us to define the appropriate solutions to face the new challenges and achieve our ambitious goals.

\author{
Alberto del Bimbo \\ Università di Firenze \\ Editor-in-Chief
}

